\title{
Análise das precipitações pluviais em Rio do Sul, Santa Catarina.
}

\author{
Analysis of rainfall in Rio do Sul, Santa Catarina.
}

Pedro Germano Murara* Priscilla Ikefuti**

\section{Resumo:}

A precipitação é um dos elementos climáticos que exerce maior influência sobre as condiçôes ambientais. $\mathrm{O}$ estudo objetivou analisar a variabilidade das precipitaçôes pluviais no município de Rio do Sul, Santa Catarina. Por meio da reconstrução de série de dados, foi possível analisar 75 anos de registros de precipitação pluvial. Os resultados identificaram a estação de verão como mais chuvosa e o outono pelo período de diminuição nos totais de chuva, no entanto, as chuvas são mais intensas na estação de inverno. O fenômeno ENOS apresenta influência na variabilidade interanual das precipitaçôes, contudo, não é decisivo para sua variabilidade.

\section{Abstract:}

Precipitation is one of the climatic elements that exert the greatest influence on environmental conditions. The objective of this study was to analyze the rainfall variability in the city of Rio do Sul, Santa Catarina. Through the reconstruction of data series, it was possible to analyze 75 years of records of rainfall. The results identified the summer season as rainier and autumn by the period of decline in totals rainfall, however, the rains are more intense in the winter season. The ENSO phenomenon has an influence on the interannual rainfall variability, although, it is not decisive for its variability 


\section{INTRODUÇÁO}

Decorrente da sua propriedade física de mudança de estado, a água, substância imprescindível para a vida, está presente na atmosfera e constitui um dos elementos climáticos que exerce maior influência sobre as condiçóes ambientais. As precipitaçóes pluviais tem grande importância para o abastecimento de água, na agricultura como benefícios para a sociedade, ou malefícios quando de sua ausência.

Compreender a variabilidade das precipitaçóes pluviais se faz necessário pois, quando de sua intensidade nos espaços urbanos, diferentes setores da economia e da sociedade têm grandes danos e perdas no que confere os transtornos à circulação de transportes e pessoas, a comunicação, as atividades serviços, e ainda, problemas vinculados a saúde da população.

Mesmo com esforços de estudos e pesquisas para cada vez mais compreender a dinâmica atmosférica, temos que reconhecer que a abordagem para a análise em escala regional e locais de estudos sobre mudanças e variabilidades em condiçôes extremas de temperatura e precipitação ainda são escassas. Uma das principais razóes é dada pela identificação de eventos extremos que requerem séries temporais precisas, completas e espacialmente coerentes em escala diária, entretanto, os dados diários estão entre as principais dificuldades para aqueles dispostos a realizar uma análise mais detalhada (MARENGO et al., 2009).

No Brasil ou em outros países da América do Sul, as maiores dificuldades estáo relacionadas à ausência de estações de longo prazo e também à baixa qualidade das séries de dados. Embora se reconheça que variaçóes de longo prazo em séries temporais podem ser identificadas não apenas por mudanças do tempo e do clima "mas também por mudanças na localização das estações, instrumentos, fórmulas utilizadas para calcular os meios, observando as práticas e ambiente da estação" (ACQUAOTTA E FRATIANNI, 2014, p.20). Portanto, o primeiro passo para uma análise climática é um rigoroso controle de qualidade e avaliação da homogeneidade do conjunto de dados.

Os primeiros estudos sobre a dinâmica climática e a variabilidade dos elementos climáticos para toda região Sul do Brasil destacavam uma homogeneidade no clima (NIMER, 1971). Nimer (1971) constatava uma uniformidade "no que se refere à pluviometria", com médias anuais variando entre 1.250 a $2.000 \mathrm{~mm}$, destacando os meses de agosto, setembro e outubro para concentração máxima da precipitação. Em contrapartida, os meses de abril, maio, junho e julho foram identificados como meses de menores registros de chuvas.

Nery (2005) em um estudo sobre a dinâmica climática da regiáo Sul do Brasil, identificou anomalias negativas e positivas de precipitação para algumas localidades dos estados de Paraná e Santa Catarina, principalmente associados ao fenômeno ENOS. O autor apresenta a importância do ENOS na variabilidade das chuvas na regiáo, porém destaca que este náo é um fenômeno determinante para a ocorrência das precipitaçóes pluviais no Sul do Brasil.

Um estudo elaborado por Grimm (2009), destaca diferenças na variabilidade das precipitaçôes para o Sul do Brasil. Segundo a autora,

\begin{abstract}
Ao norte domina o típico regime de monção, com estação chuvosa iniciando-se na primavera e terminando no início do outono, resultando em grande diferença de precipitação entre verão e inverno, enquanto ao sul há distribuição aproximadamente uniforme de chuva ao longo do ano e o regime é mais característico de latitudes médias, com chuvas relativamente mais fortes no inverno (GRIMM, 2009, p. 259).
\end{abstract}

A explicação para o contraste nos regimes de precipitação está na situação geográfica na qual se localiza a região Sul, cujos efeitos topográficos (barreiras, vales e serras) associam-se na distribuição diferenciada das chuvas para a parte Subtropical (região Sul) do Brasil (GRIMM, 2009; JORGE, 2015).

Monteiro, M. (2001) em sua caracterização climática para o estado de Santa Catarina, destaca a estação de verão como a mais chuvosa para o estado. Segundo o autor, o aumento da temperatura na estação resulta em convecções e pancadas de chuva, principalmente no período da tarde. Sem descartar os sistemas frontais que contribuem na organização e intensificação da convecção, resultando em tempestades severas. No outono as chuvas tendem a diminuir, devido ao menor aquecimento quando comparado com o verão. Não há a mesma repercussão das chuvas convectivas e no outono, os bloqueios atmosféricos impedem a passagem dos sistemas frontais, que são desviadas para o oceano, diminuindo os registros de chuvas no estado de Santa Catarina (MONTEIRO e FURTADO, 1995).

Ainda segundo o autor, no inverno, sob a incursão das frentes frias que tendem a deslocar-se principalmente pelo continente, há uma elevação nos totais pluviais, pouco superior ao outono, diferenciando o litoral com tempo mais estável devido ao fortalecimento da Alta Subtropical e, por conseguinte, apresentando registros de precipitaçóes inferiores quando comparado com o interior do estado (MONTEIRO, M., 2001).

Por fim, Monteiro M. (2001) caracteriza a pri- 
mavera pelos menores registros de precipitação pluvial, mesmo com a ocorrência de uma atmosfera mais instável devido, principalmente, a maior atuação dos Sistemas Complexos de Mesoescala (SCM), porém, estes atuando principalmente no interior do estado de Santa Catarina. Diante do apresentado, os trabalhos de Monteiro, M. (2001) e Monteiro e Furtado (1995) reforçam a diferenciação na espacialização das chuvas para a região Sul do Brasil.

Oscilaçóes climáticas interanuais das precipitação pluviais para a região Sul do Brasil estão relacionadas a atuação do fenômeno El Niño-Oscilação Sul (GRIMM, 2009). Quando da sua atuação, a fase positiva do fenômeno, o El Niño, resulta em aumento nos registros de precipitação pluvial e, em contrapartida, quando da manifestação da fase negativa, La Niña, registra-se diminuição no registro das precipitaçóes pluviais para a regiāo Sul do Brasil (BARROS et al., 2002; GRIMM, 2003)

\section{LOCALIZAÇÁO DA ÁREA DE ESTUDO}

O estado de Santa Catarina é frequentemente afetado por sistemas climáticos que resultam em eventos de chuvas intensas. A Bacia do Rio Itajaí tem sido cenário de intensos episódios de chuva que têm uma in- fluência significativa sobre o aumento do fluxo de rios causando inundaçóes e deslizamentos de terra que afetam diretamente a população local. Dados da Secretaria de Estado de Infraestrutura de Santa Catarina (2016) afirmam que inundações e deslizamentos ocorreram na Bacia do Rio Itajaí desde o início de sua colonização, há cerca de 150 anos (HERRMANN, 2014). O município de Rio do Sul (Figura 1) está localizado na mesorregião do Vale do Itajaí e ocupa uma área de aproximadamente $260 \mathrm{~km} 2$ composta por uma população de pouco mais de 68 mil habitantes (IBGE, 2016).

Estudos sobre as chuvas em Rio do Sul foram realizados por Eli et al. (2013) e Hillesheim e Neves (2015) que identificaram distribuição uniforme para as precipitaçóes pluviais ao longo do ano, sem a identificação de períodos caracterizados por estação seca. Eli et al. (2013) identificaram distribuição anual $736,7 \mathrm{~mm}$ e 2669,4mm, média de $1458,7 \mathrm{~mm}$. Com média mensal de $121,56 \mathrm{~mm}$, os autores caracterizaram as estaçóes de primavera e veráo como mais chuvosa, sendo responsável por $57,2 \%$ da precipitação anual $(834,35 \mathrm{~mm})$. Já as estações de outono e inverno apresentaram uma variação constante das chuvas, representando $42,8 \%$ da média da precipitação anual. Hillesheim e Neves (2015) identificaram média mensal $133,7 \mathrm{~mm}$, embora desta-

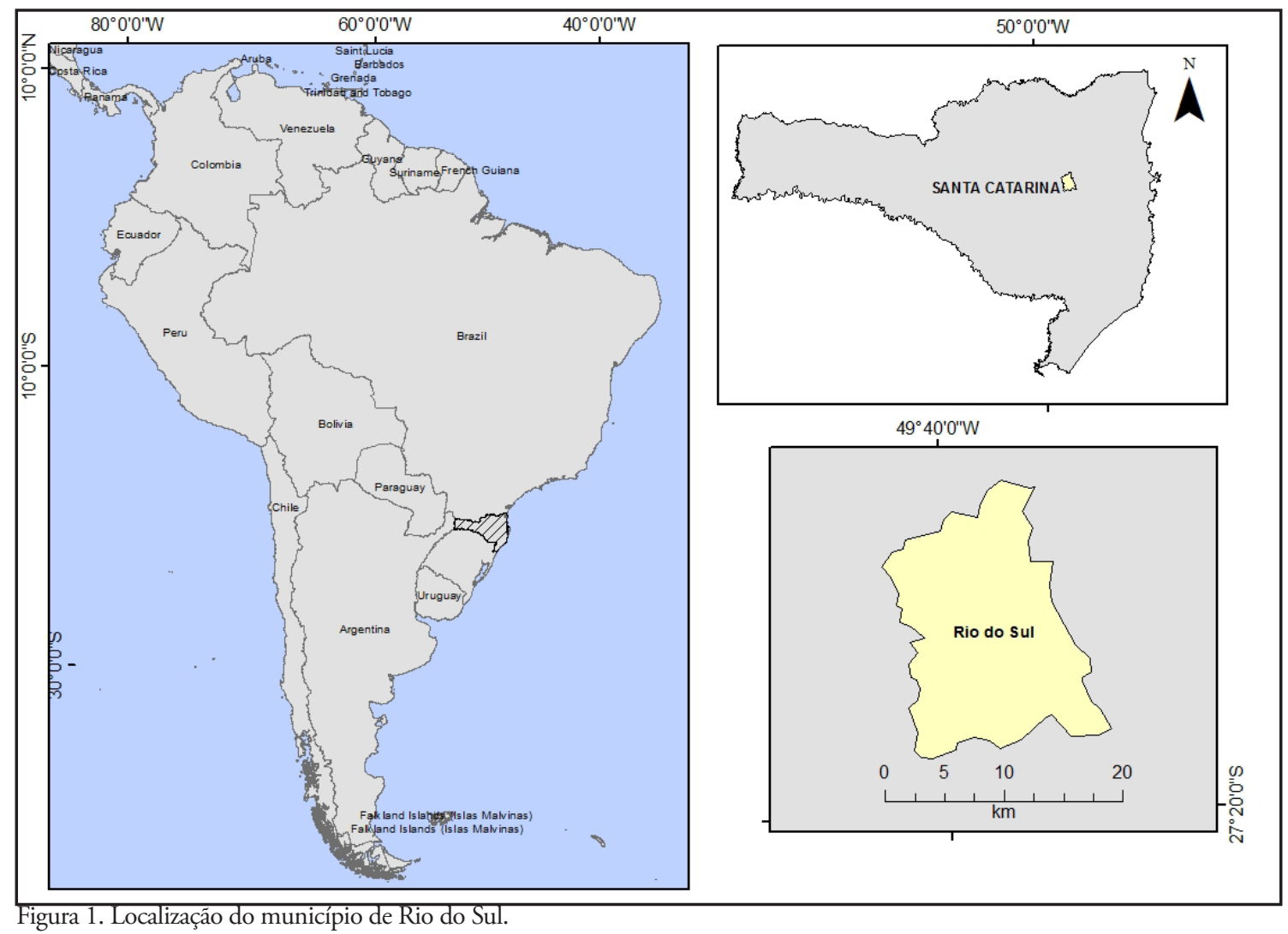

Geografia, Ensino \& Pesquisa, Vol. 21 (2017), n.3, p. 186-195

ISSN: 2236-4994 DOI: 10.5902/2236499425669 
quem um diminuiçáo das precipitaçóes no triênio abril-maio-junho e, chuvas acima da média mensal para os meses de janeiro, fevereiro e outubro.

Neste contexto, o presente artigo realizou uma revisão da análise e caracterização das precipitaçôes pluviais no município de Rio do Sul, utilizando-se de dados diários, para melhor compreender as características da precipitação em escalas diárias, mensais, sazonais e anuais, caracterizando sua variabilidade e tendências.

\section{PROCEDIMENTOS METODOLÓGICOS}

Os dados diários de precipitação pluvial foram obtidos por meio do acesso ao banco de dados Hidroweb, da Agência Nacional das Águas (ANA). Foram identificadas três postos pluviométricas (Tabela 1) com dados diários. As séries históricas foram submetidas a análise de qualidade e controle de dados e informaçôes para identificação de falhas e/ou lacunas de acordo com metodologia utilizada por Acquaotta e Fratianni (2014).

A análise do controle de dados envolve em um primeiro momento pesquisa histórica. Realizou-se contato com a ANA para identificar os motivos das ausências de dados nas séries históricas. A agência informou, por meio de laudos técnicos, que as faltas de dados ocorreram devido a algumas de suas estaçôes passaram ao longo dos anos por mudanças de localidade, assim como, alteraçóes nos aparelhos de coleta de dados. E ainda, algumas estaçóes deixaram de funcionar e outras passaram a coletar dados na mesma localidade interferindo, portanto, na série histórica. Atualmente, apenas um posto pluviométrico está em funcionamento. Porém, de posse das séries históricas efetuou-se análise de consistência para identificaçáo de possíveis erros nas séries.

O segundo passo da análise e controle de qualidade dos dados foi a verificação de possíveis lacunas nas séries diárias de precipitação das três estaçôes. Para estimar o hiato, calculamos as séries mensais e anuais. Foram criados os valores mensais somente se pelo menos $80 \%$ dos dados diários estiverem disponíveis, igual a um intervalo de 6 dias não consecutivos (KLEIN TANK et al., 2002; SNEYERS, 1990) e para os valores anuais, pelo menos, 96\% dos dados diário, igual a um intervalo de quinze dias náo consecutivos (ACQUAOTTA et al., 2009; KLEIN TANK e KÖNNEN, 2003; VENEMA et al., 2012).

A análise e reconstrução da séries foi realizada por meio da metodologia de Comparação das Chuvas - Co:Rain (GUENZI, et al., 2015). Essa metodologia mostra descontinuidade entre os pares de séries, destacando não só a diferença média entre os valores diários mas analisando como foram registrados classes diversas de eventos chuvosos, fracos, pesados ou extremos (ACQUAOTTA et al., 2015). É necessário que haja um período contínuo (mínimo de um ano de dados), em ambas as séries, para que seja possível comparar os valores. E ainda, a sobreposição só é possível para estaçôes cuja diferença de elevação entre os pontos comparados não seja superior a $200 \mathrm{~m}$ e a distância entre os pontos não ultrapasse o raio de $20 \mathrm{~km}$ (BIANCOTTI et al., 2005; ISOTA et al., 2013).

A fim de possibilitar uma comparação direta, todos os valores que estavam ausentes em uma das séries de dados também foram definidos como ausentes na sua contraparte antes da execução das análises estatísticas serem calculadas. Além disso, os valores diários de precipitação inferior a $1 \mathrm{~mm}$ não foram considerados para evitar que um conjunto de valores com pequenas alterações refletisse na precisão de medição e análise (WANG, et al., 2010; ACQUAOTTA et al., 2015).

O Co:Rain utiliza-se de testes não-paramétricos aplicado aos valores diários para avaliar as relações preliminares entre os pares de séries. O erro médio quadrático é utilizado para identificar a diferença média entre as séries, enquanto que o coeficiente de correlação de Spearman é utilizado para avaliar o coeficiente de correlação. O teste de Kolmogorov-Smirnov é aplicado para determinar se dois conjuntos de dados poderiam ter vindo da mesma distribuição, enquanto que o teste de pontuação de Wilcoxon é considerado para determinar

Tabela 1. Postos pluviométricos utilizados.

\begin{tabular}{cc} 
ID do posto pluviométrico & Recorte temporal \\
\hline 2749008 & $1941-1980$ \\
2749024 & $1944-1990$ \\
2749039 & $1979-2015$ \\
\hline \hline
\end{tabular}

Fonte: ANA (2016) 
se duas amostras tem medianas idênticas. Utiliza-se um nível de significância $\mathrm{p}=5 \%$ para todos os testes.

O cálculo do índice de precipitação para compreender a quantidade de chuva que ocorrem ao longo dos dias foi calculado utilizando-se dos dados diários. Foram somados os totais diários de precipitação e dividido pelo número de dias em que ocorrem registros de chuva. Essa divisão da quantidade total de precipitação pluvial pelo número de dias de sua ocorrência gera um valor que permite identificar no mês ou, na estação do ano, como se deu a quantidade de chuvas pelo número de dias em que ocorre a mesma.

Considerou-se para as estaçóes do ano, o triênio dezembro, janeiro e fevereiro como representativo de verão. Os meses de março, abril e maio foram identificados como outono, seguidos pelos meses de junho, julho e agosto como estação de inverno e, setembro, outubro e novembro como representantes da primavera.

Para identificação da ocorrência do ENOS (El Niño Oscilação Sul), foi consultado o National Weather Service - Climate Prediction Center (NOAA, 2016).

\section{RESULTADOS}

Conforme figura 2, os meses mais chuvosos são janeiro, fevereiro e outubro, este resultado já foi apontado por Hillesheim e Neves (2015). Os autores ainda identificam os triênio de abril-maio-junho pelos menores registros de precipitação. A diferença entre o mês mais chuvoso (janeiro - 163,4 mm) e o menos chuvoso (abril - 83,3 mm) revela uma diferença de 80,1 $\mathrm{mm}$. Portanto, o município de Rio do Sul não apresenta homogeneidade na distribuição das chuvas ao longo do ano. Há uma diminuição das precipitaçóes pluviais nos meses de abril e maio, cujas médias registram valores inferiores a 100 milímetros (Figura 2).

A redução das precipitaçóes no triênio abril, maio e junho está associada à atuação do Anticiclone Subtropical do Atlântico Sul (ASAS), que possui seu centro de ação nas proximidades do Trópico de Capricórnio, sobre o oceano Atlântico, exercendo influência sobre a parte leste da América do Sul (Figura 3). No entorno de seu centro o ar é estável devido à subsidência. A maior estabilidade deste anticiclone no inverno chega muitas vezes a impedir a entrada de frentes frias no Sul do Brasil (MONTEIRO, 2001; SACCO, 2010).

O ASAS está associado à atuação da Massa de ar Tropical Atlântica (Mta), que caracteriza-se por altas temperaturas e elevada umidade devido a sua intensa radiação solar e gênese sobre o oceano (NIMER, 1966). Entretanto, mesmo com essas características, o sistema não gera precipitação significativa de chuva, pois a umidade e nebulosidade associada a ele se restringe a uma faixa estreita próximo ao litoral (SACCO, 2010).

Durante a estação de verão, o aquecimento do continente e a alta disponibilidade de umidade, propiciam condiçóes de instabilidade na atmosfera. $\mathrm{O}$ ar aquecido por ser menos denso, ascende, transportando umidade em altitude, o que favorece a formação de nuvens espessas, e consideráveis volumes de chuva. São as chuvas convectivas típicas de verão. Nessas condiçóes atmosféricas, o ASAS encontra-se reduzido ao Oceano Atlântico. Mesmo com seu centro afastado do continente nesta época, a Alta Subtropical costuma avançar sobre o Brasil Central na estação chuvosa, o que acarreta na inibição da atividade convectiva, por consequência, redução da precipitação e aumento das temperaturas (NIMER, 1966). Portanto, a atuação do ASAS e por

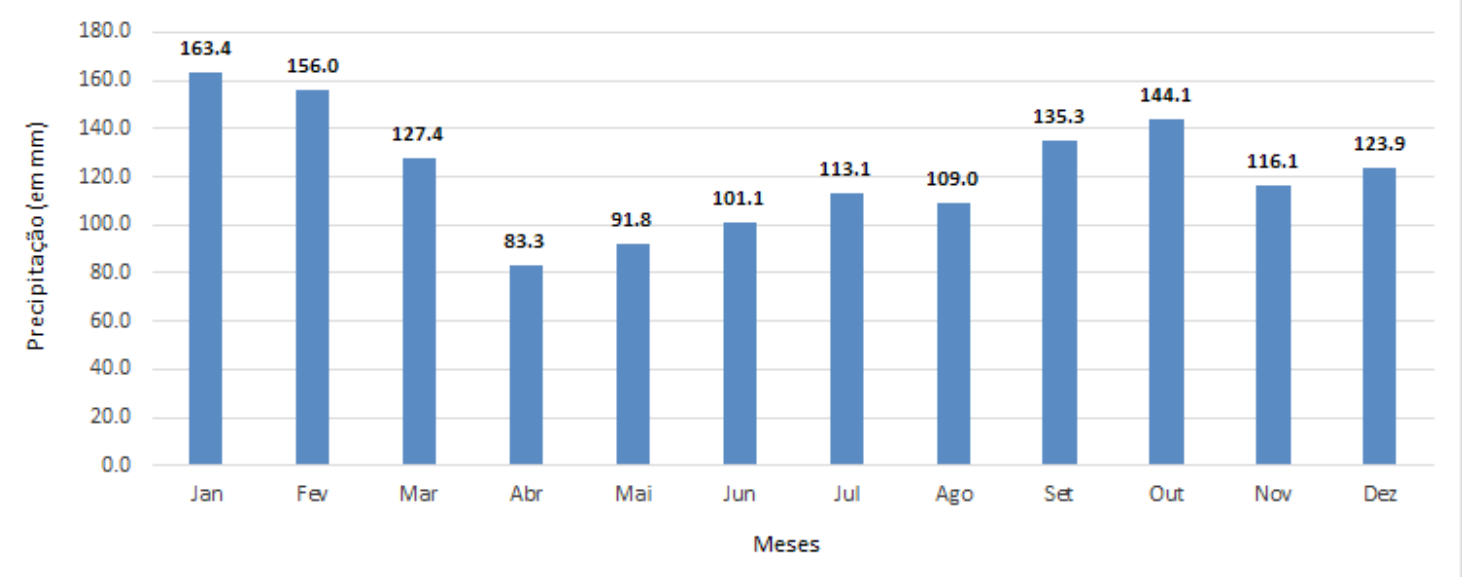

Figura 2. Distribuição mensal média das precipitaçôes pluviais, período de 1941-2015 em Rio do Sul, SC. Fonte: ANA (2016) 


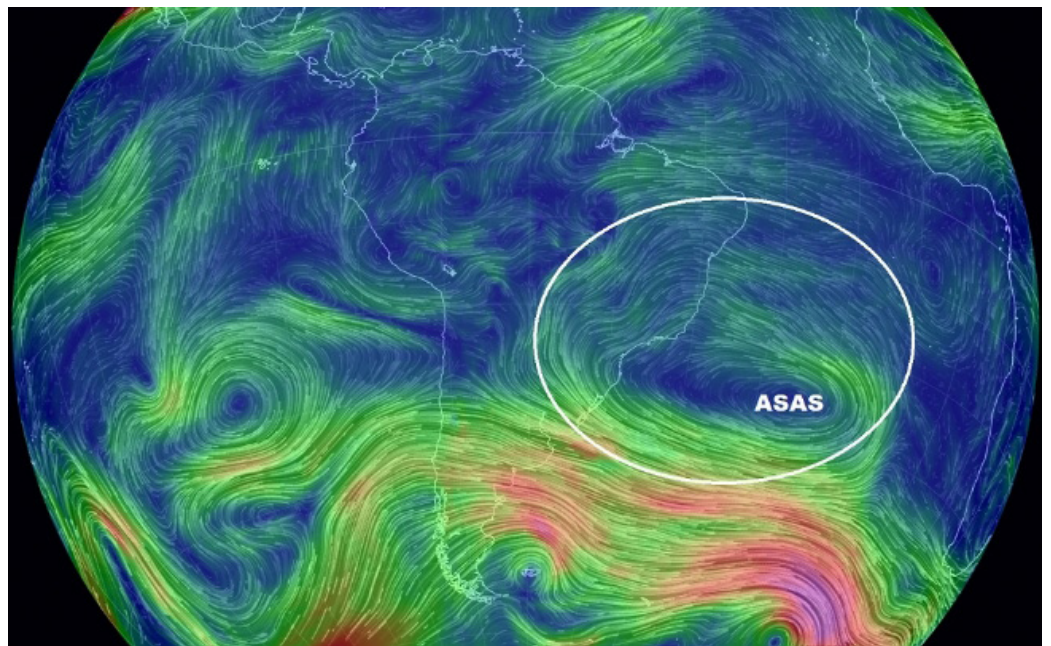

Figura 3. Identificação do Anticiclone Subtropical do Atlântico Sul - ASAS.

Fonte: http://earth.nullschool.net/

consequência da Mta repercutem na diminuição das precipitaçóes em Rio do Sul. Importante destacar que o ASAS é responsável pelos chamados bloqueios atmosféricos que resultam em período de estiagem (ausência de precipitação) uma vez que este dificulta a trajetória de outros sistemas condutores de chuvas (SACCO, 2010). A elevação das precipitaçóes no mês de julho (estação de inverno) está associada as frentes frias. Quando do encontro da massa de ar polar (fria e mais densa) com uma massa de ar mais aquecida (quente e menos densa) há como resultado a formação de uma zona de instabilidade identificada como Frente Fria (FF).

De fácil identificação por imagens de satélite, as frentes frias são caracterizadas pela presença de nuvens na direção NO-SE comumente com a formação de um vórtice na sua porção mais meridional (Figura 4).

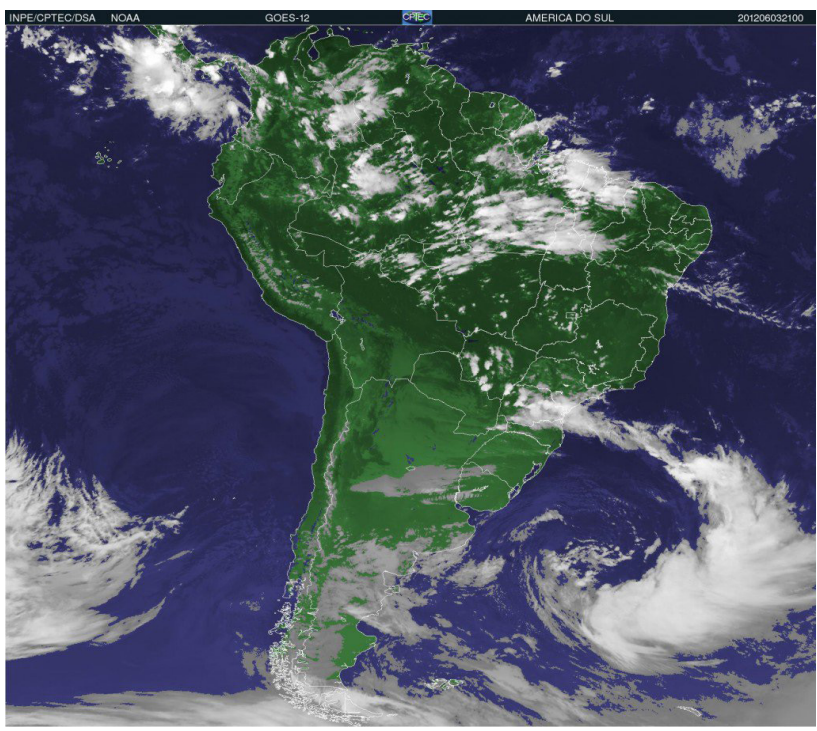

Figura 4. Identificação da frente fria. Fonte: INPE/CPTEC
Rodrigues et al., (2004) em estudo da climatologia das frentes frias identificaram, em média, a atuação de 3 a 4 frentes com intervalo de 8 dias ao longo dos meses. Este sistema influência nos regimes de precipitação e temperaturas de grande parte do país, porém, é na estação de inverno que as frentes frias atuam com maior intensidade (MENDONÇA, 2002; GRIMM, 2009).

A distribuição anual dos totais de precipitação é representada nas figuras 5, cuja média do total anual é de $1457,37 \mathrm{~mm}$. Os anos que se destacam pelos registros acima da média foram: $1972(2669,4 \mathrm{~mm}) ; 1980$ (2086,6mm); 1983 (2615,1 mm); 1990 (2221,4mmm); e 2011 (2002,8mm). Essas anomalias positivas de precipitação podem ser explicadas pela atuação do índice ENOS que nos anos de 1972 (abril a dezembro), 1980 (janeiro a março) e 1983 (janeiro a julho) foi considerado forte. Estes resultados assinalam que fenômeno ENOS não determina a chuva na região Sul, porém, são importantes quanto à intensidade das mesmas (NERY, 2005).

No ano de 1972, o mais chuvoso da série histórica $(2669,4 \mathrm{~mm})$, as precipitaçôes ocorrem principalmente no período compreendido entre os meses de junho, julho e agosto, totalizando para o triênio $990,9 \mathrm{~mm}$. Para este ano, em específico, o inverno foi a estação na qual ocorreram os maiores registros de chuva.

Os anos que se destacam pelos registros abaixo da média foram: 1944 (862,8mm); 1962 (953,3mmm) 1964 (736,7mmm); 1968 (870mm); 2006 $(1071,6 \mathrm{mmm})$. Essas anomalias negativas de precipitação respondem pela atuação do índice ENOS (La Niña) para os anos de 1964 (janeiro a março), 1968 (outubro a dezembro) e 2006 (agosto a dezembro). Portanto, essas oscilações climáticas interanuais no regime de precipitação são explicados, em parte, em razão dos episódios de 


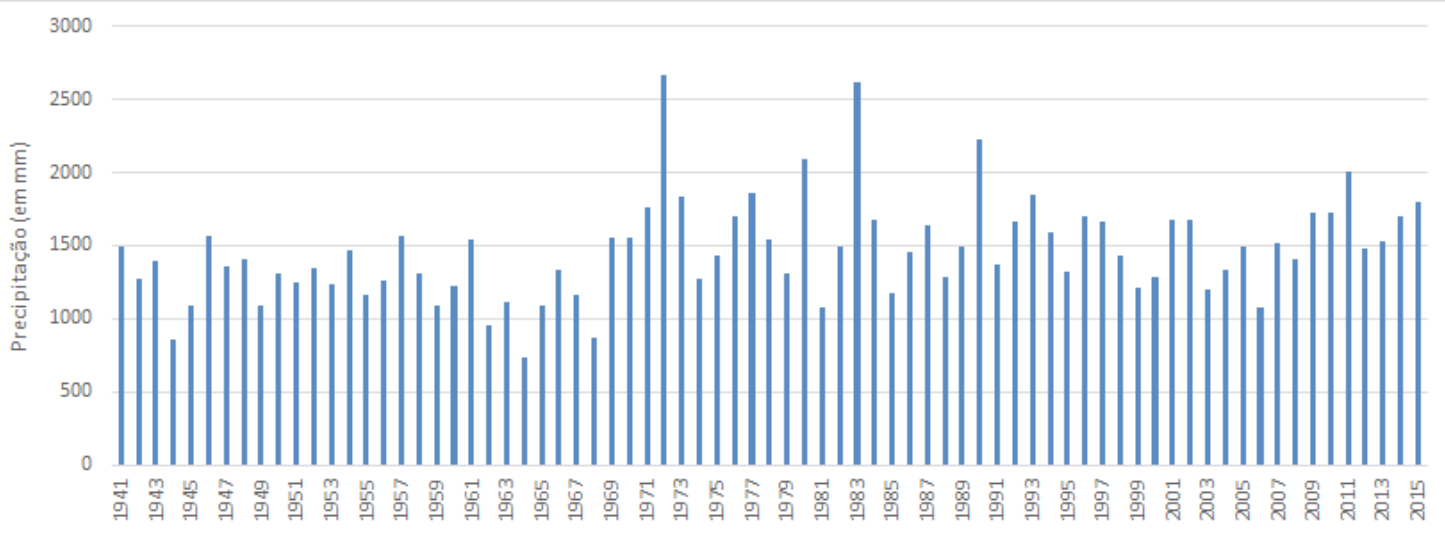

Anos

Figura 5 .Distribuição anual das precipitações pluviais em Rio do Sul, período de 1941-2015.

Fonte: ANA (2016).

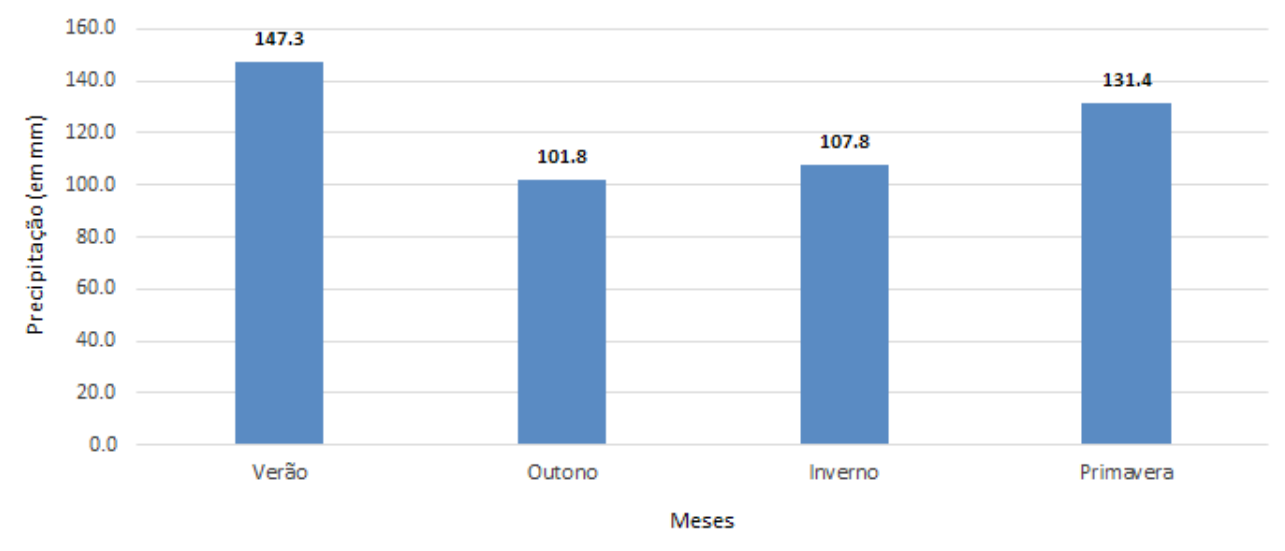

Figura 6. Média das precipitaçôes pluviais nas estaçôes do ano, Rio do Sul, período de 1941-2015. Fonte: ANA (2016).

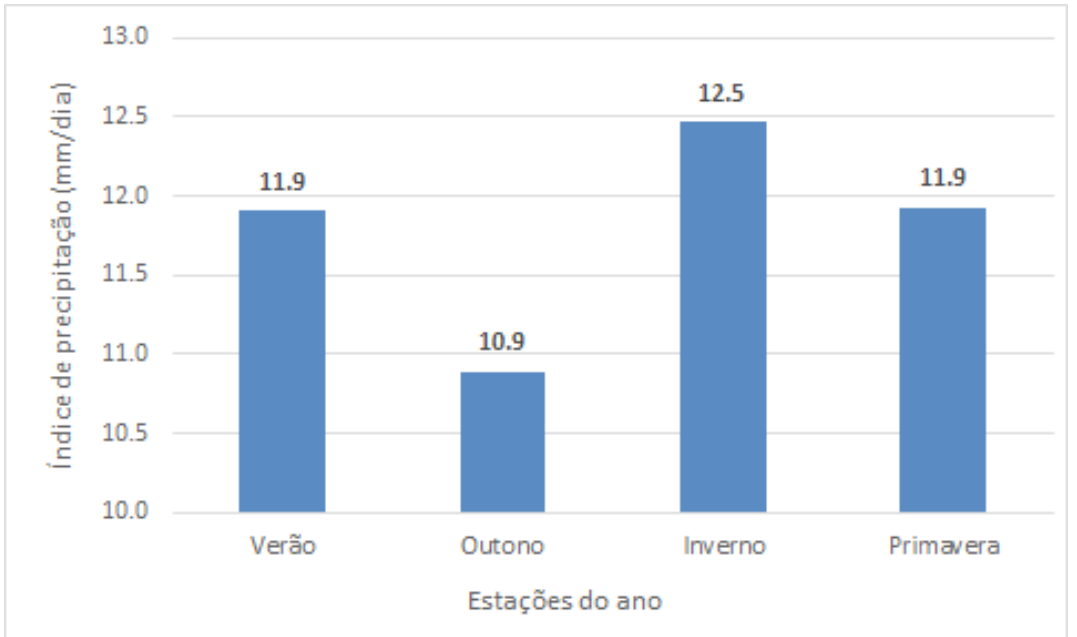

Figura 7. Índice de precipitação pluvial, Rio do Sul, período de 1941-2015. Fonte: ANA (2016). 
El Niño e La Niña (GRIMM, 2009).

A sazonalidade das precipitaçóes (Figura 6) evidencia o verão como a estação mais chuvosa (média de $147,13 \mathrm{~mm}$ ), seguido pela estação de primavera (média de $131,4 \mathrm{~mm}$ ). As estações de outono e inverno registram médias de precipitação muito similares (média de 101,8 e $107,8 \mathrm{~mm}$, respectivamente), porém, o outono é caracterizado pelos menos registros de chuva.

No entanto, embora a estação de verão seja a mais chuvosa (Figura 6) o índice de precipitaçáo revelou-se maior na estação de inverno (Figura 7). Ou seja, o total de precipitaçóes que ocorre no período de veráo indica uma distribuição homogenia ao longo dos dias, maior número de dias de chuvas para um período em que ocorrem os maiores registros de precipitação. Em contrapartida, o total de precipitação na estação de inverno, embora inferior a estação de verão, ocorre em um número de dias reduzido, logo, um alto índice quando comparado com as demais estaçóes do ano (Figura 7). Este resultado sugere a ocorrência de chuvas concentradas e, portanto, indicando este período como favorável para ocorrência de eventos envolvendo precipitaçóes intensas.

\section{CONSIDERAÇÓES FINAIS}

Com objetivo de compreender a variabilidade das precipitaçôes que ocorrem no município de Rio do Sul, o artigo contribui para estudos que visem o entendimento da dinâmica atmosférica na mesorregião do Vale do Itajaí. Ainda no âmbito das dinâmicas climáticas, a utilização de dados em escala diárias e o rigor no controle de qualidade e na avaliaçáo da homogeneidade do conjunto dos dados constitui-se em uma temática que deve ser constantemente explorada nas pesquisas de cunho climático, principalmente a partir da realizada nacional em que as dificuldades de estáo relacionadas à ausência de estaçóes de longo prazo e também à baixa qualidade das séries de dados.

As precipitaçôes pluviais que ocorrem em Rio do Sul apresentam um maior total nos meses de janeiro, fevereiro e outubro, e os menores registros para os meses de abril-maio-junho. $\mathrm{Na}$ variabilidade sazonal, o verão destaca-se pelos maiores registros de precipitação pluvial e o outono pelo período de menor totais de chuva. $\mathrm{Na}$ estação de primavera ocorrem precipitaçóes superiores a estação de inverno, configurando chuvas que possuem um mínimo na estação de outono e apresentam maiores registros nas estaçóes seguintes, inverno, primavera e verão, respectivamente. Embora a estação de verão seja caracterizada pelos totais máximos de precipitação, as chuvas intensas ocorrem no inverno, seguido pelas estaçóes da primavera e verão. A estação do outono é caracterizada pelos menores registros de precipitação e de chuvas menos intensas, porém, conforme a bibliografia utilizada e os resultados aqui apresentados, não há um período de seca e/ou estiagem definido para o município de Rio do Sul.

O fenômeno ENOS apresenta influência na variabilidade interanual das precipitaçóes, porém, não é decisivo. Anos identificados pelo registro de precipitação acima da média por vezes apresentam relação com a atuação do El Niño, o mesmo resultado foi verificado para a atuaçáo da La Niña. O estudo da variabilidade das precipitaçóes pluviais em Rio do Sul motiva os autores a continuar projetos em andamento na área de estudo, e que futuramente, poderão relacionar as chuvas com o processo de produção do espaço urbano e como consequência, eventos de inundaçôes que assolam o município de Rio do Sul e a mesorregiâo do Vale do Itajaí.

\section{REFERÊNCIAS}

ACQUAOTTA, F. et al. On the continuity and climatic variability of meteorological stations in Torino, Asti, Vercelli and Oropa. In: Meteorology and Atmospheric Physics. 103, p. 279-287, 2009.

ACQUAOTTA, F. \& FRATIANNI, S. The importance of the quality and reliability of the historical time series for the study of climate change. In: Revista Brasileira de Climatologia, n. 10, v. 14 - Jan/Jul, 2014.

ACQUAOTTA, F.; VENEMA, V.; FRATIANNI, S. Assessment of parallel precipitation measurements networks in Piedmont, Italy. In: International Journal of Climatology, n. 10, v. $14-\mathrm{Jan} / \mathrm{Jul}, 2015$.

ACQUAOTTA, F. et al. Co.Rain - Comparing Series of Rain. CoRain v1.0 [Data set] Zenodo. Disponível em: http://doi.org/10.5281/zenodo.58478, 2015.

AGÊNCIA NACIONAL DE ÁGUAS - ANA. Série histórica. Disponível em: http://hidroweb.ana.gov.br/ Acesso em 15 janeiro 2017.

BARROS, V.R.; GRIMM, A.M.; DOYLE, E.M.E. Relationship between temperature and circulation in Southeastern South America and its influence from El Niño and La Niña events. In: Journal of the Meteorological Society of Japan, 80, 21-32, 2002.

BIANCOTTI, A.; DESTEFANIS, E.; FRATIANNI, S.; MASCIOCCO, L. On precipitation and hydrology of Susa Valley (Western Alps). In: Geografia Fisica e Dinamica del Quaternario. (Itália) suppl. VII: 51-58, 2005. 
DEFESA CIVIL DO ESTADO DE SANTA CATARINA - DCESC. Desastres Naturais. Disponível em: http://www. defesacivil.sc.gov.br/ Acesso em: 14 dez. 2016

ELI, K. PITZ, et al Análise da distribuição da frequência de precipitaçáo em diferentes intervalos de classes para Rio do Sul/SC. Enciclopédia Biosfera. Centro Científico Conhecer - Goiânia, v. 9, n. 16, p. 106, 2013.

GUENZI, D. et al. CoRain: a free and open source software for rain series comparison. Earth Science Informatics, submitted, 2016.

GRIMM, A. M. The El Niño impact on the summer monsoon in Brazil: regional processes versus remote influences. In: Journal of Climate, 16, 263-280, 2003.

GRIMM, A. M.; Clima da Região Sul do Brasil. In: CAVALCANTI, I.F.A.; FERREIRA, N.J.; SILVA, M.G.A.; DIAS, M.A.F.S. (Org.). Tempo e Clima no Brasil. São Paulo: Oficina de Textos, 2009.

HERRMANN, M.L.P. (org). Atlas de Desastres Naturais do Estado de Santa Catarina: período de 1980 a 2010. 2a ed. atual. e rev. - Florianópolis: IHGSC/Cadernos Geográficos, 2014.

HILLESHEIM, W.T.; NEVES, L.O. Análise frequencial e distribuição das chuvas na região de Rio do Sul/SC. In: Ciência e Natura, Santa Maria, v. 37 Ed. Especial SIC, 2015, p.119-124.

INSTITUTO BRASILEIRO DE GEOGRAFIA E ESTATÍSTICA - IBGE. IBGE Cidades. 2016. Disponível em: http://www.cidades.ibge.gov.br Acessado em: 15 janeiro 2016.

ISOTTA, F. et al. The climate of daily precipitation in the Alps: development and analysis of a high- resolution grid dataset from pan-Alpine rain-gauge data. In: International Journal of Climatology, v. 34, p.1657-1675, 2013.

JORGE, F.V. A dinâmica pluvial do clima subtropical: variabilidade e tendência no sul do Brasil. 2015. 343p. Tese (Doutorado em Geografia) - Setor de Ciências da Terra, Universidade Federal do Paraná, Curitiba.

KLEIN TANK, A.M.G.; KÖNNEN, G.P. Trends in indices of daily temperature and precipitation extremes in Europe, 1946-99. In: International Journal of Climatology, v.16, p. 3665-3680, 2003

KLEINTANK, A.M.G., WIJNGAARD, J.B.; KÖNNEN, G.P. Daily surface air temperature and precipitation dataset 1901-1999 for European Climate Assessment (ECA). In: International Journal of Climatology, v. 22, p.1441-1453, 2002.
MARENGO, J.A.; NOBRE, C.A. Clima da Região Amazônica. In: CAVALCANTI, I.F.A.; FERREIRA, N.J.; DA SILVA, M.G.A.J.; SILVA DIAS, M.A.F. (Orgs.). Tempo e Clima no Brasil. São Paulo, SP: Oficina de Textos. p.197212, 2009.

MENDONÇA, M. A dinâmica têmporo-espacial do clima subtropical na região conurbada de Florianópolis/SC. 2002. 343p. Tese (Doutorado em Geografia) - Departamento de Geografia, Faculdade de Filosofia, Letras e Ciências Humanas, Universidade de São Paulo, São Paulo.

MONTEIRO, M.; FURTADO. S.M. O Clima do Trecho Florianópolis - Porto Alegre: Uma abordagem Dinâmica. In: Revista GEOSUL, n. 19/20, 1995.

MONTEIRO, M. Caracterização climática do estado de Santa Catarina: uma abordagem dos principais sistemas atmosféricos que atuam durante o ano. In: Revista GEOSUL. Revista do Departamento de Geociências da UFSC, Florianópolis, v. 16, no 31, p 69-78, 2001.

NIMER, E. Circulação Atmosférica do Brasil. Contribuição ao Estudo da Climatologia no Brasil. In: Revista Brasileira de Geografia. p. 232-250, Julho-Setembro, 1966.

NIMER, E. Climatologia da Região Sul do Brasil. Instituto Brasileiro de Geografia e Estatística, Rio de Janeiro, Rio de Janeiro. p. 03-65, 1971.

NATIONAL OCEANIC AND ATMOSPHERIC ADMINISTRATION. NATIONAL WEATHER SERVICE - NOAA. Climate Prediction Center. El Niño/Southern Oscillation (ENSO). Historical El Niño/La Niña episodes (1950-present). Disponível em: http://www.cpc.ncep.noaa. gov Acessado em: 13 dezembro 2016.

RODRIGUES, M.L.G.; FRANCO, D.; SUGAHARA, S. Climatologia de frentes frias no litoral de Santa Catarina. In: Revista Brasileira de Geofísica, v. 22, n.2, p. 135-151, 2004.

SACCO, F.G. Configuraçôes atmosféricas em eventos de estiagem de 2001 a 2006 na Mesorregião Oeste de Santa Catarina. 2010. Dissertação (Mestrado) - Universidade Federal de Santa Catarina, Centro de Filosofia e Ciências Humanas. Florianópolis.

SNEYERS. On the statistical analysis of series of observations. Geneva (Suíça), World Meteorological Organization, 143, p. 192, 1990.

VENEMA, V.K.C.; MESTRE, O.; AGUILAR, E. Benchmarking homogenization algorithms for monthly data. In: Climate of the Past. v. 8, p. 89-115, 2012.

WANG, X.; CHEN, H.; WU, Y. New techniques for the detection and adjustment of shifts in daily precipitation data series. In: Journal of Applied Meteorology and Climatology, v. 49, p. 2416-2436, 2010. 


\section{Correspondência do autor:}

Pedro Germano Murara, pmurara@gmail.com

Priscilla Ikefuti

priscilla.ikefuti@yahoo.com.br

ARTIGO RECEBIDO EM: 22/05/2017

REVISADO PELO AUTOR EM: 09/05/2017

ACEITO PARA PUBLICAÇÃO EM: 09/05/2017

Geografia, Ensino \& Pesquisa, Vol. 21 (2017), n.3, p. 186-195

ISSN: 2236-4994 DOI: 10.5902/2236499425669 